\title{
Biodegradable and Bioabsorbable Inorganic Particles in Cancer Nanotechnology
}

\section{Shanta R. Bhattarai ${ }^{1 *}$ and Narayan Bhattarai ${ }^{2 *}$}

${ }^{1}$ Department of Radiation Oncology, The University of Texas: MD Anderson Cancer Center, Houston, TX, USA

${ }^{2}$ Department of Chemical, Biological and Bioengineering, and Engineering Research Center- Revolutionized Metallic Biomaterials, North Carolina A\&T State University, and Greensboro, NC, USA

Cancer is the second leading cause of death in the United States after heart disease. A total of 1,660,290 new cancer cases and 580,350 deaths from cancer were estimated to occur in the United States in 2013 [1]. Nanomedicine involves the application of nanotechnology to treatment and detection of this disease [2]. In this context, nanotechnology is almost paronymous with nanoparticles. High surface area to volume ratios associated with nanoparticles, in concert with facile surface functionalization chemistries allows the technology for loading large amounts of cargo including toxic chemotherapeutic drugs, plasmid DNA, and siRNA. For cancer disease, nanoparticles between 10 and $100 \mathrm{~nm}$ in size preferably accumulate at tumour sites due to the Enhanced Permeability and Retention (EPR) effect $[3,4]$.

The use of nanoparticle in cancer treatment often called cancer nanomedicine offers some exciting possibilities, including the possibility of destroying cancer tumors with minimal damage to healthy tissue, as well as early detection and elimination of cancer cells [5]. For late stage tumours nanomedicine also offer many possibilities for avoiding serious side effects, avoiding infusions, release drug in a sustained fashion, maintain high drug concentrations locally, reduce presence of drug in systemic blood circulation, and maintain drug stability for a longer period, etc. With these advantages and properties, nanoparticles serve as customizable therapeutic delivery devices for cancer therapy. From the delivery point of view, transporting large amounts of therapeutics to the body may display an increase in bioavailability but could result with exorbitant irrational quantities of therapeutics getting eliminated from the body with potential increase in undesired serious side effects as nephrotoxicity and hepatotoxicity. Especially for all pharmacological applications, a potential role of nanoparticles in therapeutic delivery has been focus of research activity through cancer nanotechnology that lead to a new generation of treatment options. The carrier materials selected for the delivery system are expected to be affordable, exhibit predictable release characteristics, mechanically and biologically compatible and bioresorbable with local tissue. Thus the materials properties of biodegradation and bioresorption play a vital role to select an ideal next generation delivery system. Biodegradation is the breakdown of material by the action of a living system or via enzymes and thus cells, and bioresorption is the elimination of byproducts of biodegradation from an animal organism via natural pathways. Therefore, it becomes indispensable to seek local release of therapeutics for improved efficacy and faster healing of disease from nanoparticles.

However, a major roadblock in translation of several nanoparticles to clinical practice for systemic targeting of cancer cells is their nonbiodegradable nature [5]. The accumulation and resulting long-term toxicity of nanoparticles is a major concern. In addition, sizes of nanoparticles that are used in biological applications are not small enough to be easily cleared from the body. The issue of body clearance of nano-carriers obviously needs to be considered carefully. Although there is a long list of nanoparticles under investigation, inorganic nanoparticles such as metals, metal oxides, ceramics etc., have received increased attention in the field of cancer nanotechnology because of their unique optical, magnetic, electric or mechanical properties in their nanostructures. Some key inorganic nanoparticles like calcium phosphate $(10 \sim 100 \mathrm{~nm})$, iron oxide $(5 \sim 10 \mathrm{~nm})$, silica $(3 \sim 100 \mathrm{~nm})$, zinc oxide $(3 \sim 60 \mathrm{~nm})$, zinc sulfide $(3 \sim 50 \mathrm{~nm})$, and magnesium and manganous phosphate has been extensively used for gene based drug delivery $[5,6]$.

Compared with many existing popular nanomaterials, magnesium $(\mathrm{Mg})$ based nanomaterials have many unique advantages [7]. First, $\mathrm{Mg}$ is biodegradable and bioabsorbable inorganic materials and an essential mineral for human metabolism [8], and the density of magnesium is much lower than that of gold and therefore more particles can be loaded into the target tissues. About $1 \%$ of the total body $\mathrm{Mg}$ is found in blood plasma, about a third of which is bound to proteins (as a cofactor for more than 300 enzymatic reactions) [9]. Second, Mg has low corrosion resistance which results in the rapid release of degradation products leads to the formation of harmless corrosion products, which are excreted through urine. Third, $\mathrm{Mg}$ has already become a promising implant metal and continuing to be proven excellent candidate materials for biodegradable orthopedic implants and vascular stents [10]. Fourth, the safety of the $\mathrm{Mg}$ nanoparticle lies in its degradation into magnesium ions, which are completely absorbable by the human body. Fifth, Mg is highly abundant in nature and will thus be costeffective for clinical utilization [11]. Last but not least, the market segment for $\mathrm{Mg}$ based nano material is relatively small worldwide. Hence, the magnesium or magnesium based composite material would be more promising material for future cancer therapy as a best category of therapeutic carrier materials in cancer fields.

\section{Acknowledgement}

N. Bhattarai would like to acknowledge Engineering Research Center for Revolutionizing Metallic Biomaterials (ERC-RMB) and Nanotechnology Undergraduate Education (NUE) form NSF for funding.

*Corresponding authors: Shanta R. Bhattarai, Department of Radiation Oncology, The University of Texas: MD Anderson Cancer Center, Houston, TX, USA, E-mail: sbhattarai@mdanderson.org

Narayan Bhattarai, Department of Chemical, Biological and Bioengineering and Engineering Research Center-Revolutionized Metallic Biomaterials, North Carolina A\&T State University, and Greensboro, NC, USA, E-mail: nbhattar@ncat.edu

Received March 29, 2013; Accepted April 01, 2013; Published April 03, 2013

Citation: Bhattarai SR, Bhattarai N (2013) Biodegradable and Bioabsorbable Inorganic Particles in Cancer Nanotechnology. J Nanomed Nanotechol 4: 170. doi:10.4172/2157-7439.1000170

Copyright: (C) 2013 Bhattarai SR, et al. This is an open-access article distributed under the terms of the Creative Commons Attribution License, which permits unrestricted use, distribution, and reproduction in any medium, provided the original author and source are credited. 
Citation: Bhattarai SR, Bhattarai N (2013) Biodegradable and Bioabsorbable Inorganic Particles in Cancer Nanotechnology. J Nanomed Nanotechol 4: 170. doi:10.4172/2157-7439.1000170

\section{References}

1. Siegel R, Naishadham D, Jemal A (2013) Cancer statistics. CA Cancer J Clin 63: $11-30$.

2. Service RF (2005) Nanotechnology takes aim at cancer. Science 310: 11321134.

3. Prabhakar U, Blakey DC, Maeda H, Jain RK, Sevick-Muraca EM, et al. (2013) Challenges and key considerations of the enhanced permeability and retention effect (EPR) for nanomedicine drug delivery in oncology. Cancer Res.

4. Greish K (2010) Enhanced permeability and retention (EPR) effect for anticancer nanomedicine drug targeting. Methods Mol Biol 624:25-37.

5. Schroeder A, Heller DA, Winslow MM, Dahlman JE, Pratt GW, et al. (2012) Treating metastatic cancer with nanotechnology. Nat Rev Cancer 12: 39-50.
6. Bhakta G, Mitra S, Maitra A (2005) DNA encapsulated magnesium and manganous phosphate nanoparticles: potential non-viral vectors for gene delivery. Biomaterials 26: 2157-2163.

7. Saris NE, Mervaala E, Karppanen H, Khawaja JA, Lewenstam A (2000) Magnesium. An update on physiological, clinical and analytical aspects. Clin Chim Acta 294: 1-26.

8. Vormann J (2003) Magnesium: nutrition and metabolism. Mol Aspects Med 24: $27-37$.

9. MacLeod D, MacLeod J (1999) Magnesium: physiology and pharmacology. Br $\mathrm{J}$ Anaesth 972-973.

10. Staiger MP, Pietak AM, Huadmai J, Dias G (2006) Magnesium and its alloys as orthopedic biomaterials: A review. Biomaterials 27: 1728-1734.

11. McBride ED (1938) Absorbable metal in bone surgery-A further report on the use of magnesium alloys. JAMA 111: 2464-2467. 